James E. Goehring

\title{
Politics, Monasticism, and Miracles in Sixth Century Upper Egypt
}

\section{A Critical Edition and Translation of the Coptic Texts on Abraham of Farshut}

[Politik, Klosterleben und Wunder im Oberägypten des 6. Jahrhunderts. Eine kritische Ausgabe und Übersetzung der koptischen Texte über Abraham von Farshut.]

Veröffentlicht auf Englisch.

Dieser Band enthält die kritische Ausgabe und die Übersetzung der koptischen Texte über Abraham von Farshut, den letzten koptisch-orthodoxen Klostervorsteher der pachomianischen Vereinigung in Oberägypten. Frühere Studien haben ihren Schwerpunkt auf die Ursprünge und frühen Jahre dieser ersten gemeinschaftlichen klösterlichen Bewegung gelegt. In der vorliegenden Arbeit beschäftigt sich James E. Goehring hingegen mit ihren letzten Tagen und ihrem Untergang während der Herrschaft des byzantinischen Kaisers Justinian I. im 6. Jahrhundert. Er untersucht die literarischen Eigenschaften der Texte, ihre Rolle bei der Erschaffung eines Heiligen und die historischen Ereignisse, die sie reflektieren. Geschichten von Wundern und tendenziöse Darstellungen weichen der Rekonstruktion innerer Debatten über die Entscheidungen des Konzils von Chalcedon, politischen Intrigen und schließlich der Neuordnung der kommunalen klösterlichen Bewegung in Oberägypten.

James E. Goehring Born 1950; 1968 BA from UC Berkeley; 1972 MA from UC Santa Barbara; 1981 PhD in Early Christian Studies from Claremont University; currently Professor of Religion at the University of Mary Washington in Fredericksburg, Virginia.

\section{XIV, 160 Seiten. STAC 69}

ISBN 978-3-16-152276-5

DOI 10.1628/978-3-16-152276-5

eBook PDF $64,00 €$

ISBN 978-3-16-152214-7

fadengeheftete Broschur $64,00 €$

\section{Jetzt bestellen:}

https://mohrsiebeck.com/buch/politics-monasticism-and-miracles-in-sixth-century-upper-egypt-9783161522765?no_cache=1 order@mohrsiebeck.com

Telefon: +49 (0)7071-923-17

Telefax: +49 (0)7071-51104 